\title{
Biodegradation of Total Petroleum Hydrocarbon by Molecularly Identified Bacteria Isolated From an Oilfield Wastewater in
} Nigeria

Oyibo N*, Wemedo SA, Akani NP and Ugboma CJ

Department of Microbiology, Rivers State University, Nigeria

*Corresponding author: Oyibo N, Department of Microbiology, Rivers State University, P.M.B 5080, Port Harcourt, Nigeria, Email: ntonghaoyibo@gmail.com

\section{Research Article}

Volume 5 Issue 2

Received Date: June 20, 2020

Published Date: July 03, 2020

DOI: 10.23880 /oajmb-16000164

\section{Abstract}

Biodegradation of petroleum hydrocarbon is a complex process that depends on the nature and on the amount of the hydrocarbon present. Many microbial organisms have been shown to possess the capacity to biodegrade various components of hydrocarbon. Hence this study was aimed at assessing the potential of bacterial species isolated from oilfield wastewater to biodegrade total petroleum hydrocarbon in crude oil. Oilfield wastewater was collected from an onshore oil production platform. Standard procedures were observed during collection and microbiological analysis of wastewater samples. Bacteria isolated were identified using conventional and molecular methods. The biodegradation set up was done using six conical flasks containing basal medium of mineral salt broth and crude oil as the source of energy for growth. Bacteria isolated were identified as Acinetobacter species, Enterobacter hormaechei, Myroides odaratimimus and Lysinibacillus species. Flasks of experimental set ups were inoculated with $1 \mathrm{ml}$ of individual isolate and mixed culture except the control. The biodegradation of TPH were periodically monitored for 35 days using Gas Chromatography (GC). Total viable counts (CFU/ML) obtained during the experiment ranged from $0-1.8 \times 105,1.65 \times 105-3.2 \times 106,1.90 \times 106-1.28 \times 107,1.52 \times 106-8.9 \times 106,1.13 \times 106-1.48 \times 107$, $3.4 \times 106-2.19 \times 107$ in control, Acinetobacter species, Enterobacter hormaechei, Myroides odaratimimus, Lysinibacillus species and the mixed culture treatment options respectively. The initial concentration of TPH at day 1 was $3241.47 \mathrm{mg} / \mathrm{l}$. At the end of the experiment (day 35), control, Acinetobacter species, Enterobacter hormaechei, Myroides odaratimimus, Lysinibacillus speccies and the mixed culture treatment options recorded final concentration of 2823.33, 363.72, 383.44, 284.55, 472.70 and $212.21 \mathrm{mg} / \mathrm{l}$ respectively. Highest percentage removal of $93.5 \%$ was observed in the mixed culture while the least of $12.9 \%$ was observed in the control; individual species showed significant reduction in TPH with different capability. Results showed that bacteria isolated from oilfield wastewater have the ability to degrade total petroleum hydrocarbon (TPH) and can be used in the clean-up of crude oil contaminated area.

Keywords: Biodegradation; Oilfield Wastewater; Total Petroleum Hydrocarbon; Bacteria

Abbreviations: TPH: Total Petroleum Hydrocarbon; TVBC: Total Viable Bacteria Counts.

\section{Introduction}

Biodegradation of petroleum hydrocarbon is a complex process that depends on the nature and on the amount of the hydrocarbon present. Petroleum hydrocarbon can be divided into four classes: saturated, aromatics, asphaltenes (phenols, fatty acids, ketones, esters, and porphyrins), and the resins (pyridines, quinolines, carbazoles, sulfoxides, and amides) [1]. The potential of microorganisms, pointed out in literature as agents of degradation of several compounds indicates biological treatments as the most promising alternative to reduce the environmental impact caused by hydrocarbons. It is known that the main microorganisms 


\section{Open Access Journal of Microbiology \& Biotechnology}

consuming petroleum hydrocarbon are bacteria and fungi $[2,3]$. Oilfield wastewater or produced water consists of formation and injection water that contains production chemicals generated during the production of crude oil and gas from onshore and offshore wells [4]; they also contain diverse populations of bacteria and fungi $[4,5]$. This study therefore investigated the potentials of bacteria isolated from oilfield wastewater to biodegrade total petroleum hydrocarbon in crude oil.

\section{Materials and Methods}

\section{Collection of Oilfield Wastewater Samples}

Oilfield wastewater samples were collected from an onshore oil production platforms located in Ogbia Local government Area of Bayelsa State, Nigeria. The oilfield wastewater samples were collected using $250 \mathrm{ml}$ sterile sampling bottles. Samples were collected according to the method described in Standard Methods for Water and Wastewater Analysis [6]. According to the above procedures, $250 \mathrm{ml}$ of the sterile sample bottles were filled from gentle stream of the wastewater. The sample bottles were appropriately labeled and stored in an ice packed cooler. The stored samples were immediately transported to the laboratory within 24 hours for processing and analysis.

\section{Preparation of Oilfield Wastewater Sample Inoculum}

One milliliter $(1 \mathrm{ml})$ of oilfield wastewater samples were serially diluted using one milliliter pipette by aseptically introducing $1 \mathrm{ml}$ of the oilfield wastewater into $9 \mathrm{ml}$ of sterile normal saline in a test tube to give an initial dilution of $1: 10 \mathrm{ml}\left(10^{-1}\right.$ dilution). Subsequent dilutions were done up to $10^{-3}$ dilution [7].

\section{Isolation of bacteria from Wastewater Samples}

This involved isolation of heterotrophic bacteria using nutrient agar by the spread plate technique as described by Prescott, et al. [7]. Aliquots $(0.1 \mathrm{ml})$ of serially diluted samples of $10^{-2}$ dilution were spread plated onto dried sterile nutrient agar plates in duplicates. The plates were incubated at $37^{\circ} \mathrm{C}$ for 24 hours. Representative colonies were selected and sub-cultured to purify them into pure isolates for characterization. The purified colonies represented the bacteria isolated from the oilfield wastewater samples.

\section{Molecular Identification of Bacterial Isolates}

Purified bacterial isolates were subjected to preliminary identification techniques using their colonial and morphological characteristics. Further identification employing the 16S rRNA gene was carried out. The $16 \mathrm{~S}$ rRNA regions of the rRNA gene of the isolates were amplified after extraction and quantification of the DNA using the 27F: 5'-AGAGTTTGATCMTGGCTCAG-3' and 1492R: 5'-CGGTTACCTTGTTACGACTT-3' primers on an ABI 9700 Applied Bio systems thermal cycler at a final volume of 40 microlitres for 35 cycles. The PCR mix included: the X2 Dream taq Master mix supplied by Inqaba, South Africa (taq polymerase, DNTPs, $\mathrm{MgCl}$ ), the primers at a concentration of $0.5 \mu \mathrm{M}$ and the extracted DNA as template. The PCR conditions were as follows: Initial denaturation, $95^{\circ} \mathrm{C}$ for 5 minutes; denaturation at $95^{\circ} \mathrm{C}$ for 30 seconds; annealing at $52^{\circ} \mathrm{C}$ for 30 seconds; extension at $72^{\circ} \mathrm{C}$ for 30 seconds for 35 cycles and final extension at $72^{\circ} \mathrm{C}$ for 5 minutes. The product was resolved on a $1 \%$ agarose gel at $130 \mathrm{~V}$ for 30 minutes and visualized on a blue light trans illuminator.

The sequences of the isolates were edited using the bioinformatics algorithm Trace edit; similar sequences were downloaded from the National Center for Biotechnology Information (NCBI) data base using BLASTN and was further aligned using Clustal $\mathrm{X}$. The evolutionary history was inferred using the Neighbour-Joining method in MEGA 6.0 [8]. The bootstrap consensus tree inferred from 500 replicates [9] was taken to represent the evolutionary history of the taxa analysed. The evolutionary distances were computed using the Jukes-Cantor method [10].

\section{Biodegradation Experiment}

The experiment was designed to determine the potential of some bacteria isolated from the oilfield wastewater to degrade total petroleum hydrocarbon (TPH) in crude oil.

\section{Preparation of Bacterial Inoculum}

Nutrient broth was prepared according to manufacturer's specifications after which the bacterial species were inoculated into it and incubated at $37^{\circ} \mathrm{C}$ for 24 hours to allow bacterial growth. Serial dilutions were made for each bacterial culture to determine the number of cells/ millimeter aliquot. Aliquot $0.1 \mathrm{ml}$ of appropriate dilution was spread plated out and used in the set-up designated as A, B, C, D, E and F treatment options.

\section{Composition of Biodegradation Set up}

Six conical flasks were used for the degradation experiment and were properly labeled. Each flask contained $1000 \mathrm{ml}$ of mineral salt broth, $1 \mathrm{ml}$ of the each bacterial species, and $5 \mathrm{ml}$ of crude oil sterilized by filtration method using Whatman filter paper previously sterilized in the autoclave at $121^{\circ} \mathrm{C}$ for 15 minutes. Mixed cultures of the 4 bacterial species were used for the last set up (F). The 


\section{Open Access Journal of Microbiology \& Biotechnology}

experimental set ups were presented in Table 1.

\begin{tabular}{|c|c|}
\hline Set up & Content \\
\hline A & Control (Crude oil + Mineral Salt Medium) \\
\hline B & $\begin{array}{r}\text { Acinetobacter species }\left(1 \mathrm{ml} \text { of } 1.8 \times 10^{6}\right)+\text { crude } \\
\text { oil + Mineral salt medium }\end{array}$ \\
\hline C & $\begin{array}{r}\text { Enterobacter hormaechei }\left(1 \mathrm{ml} \text { of } 2.6 \times 10^{6}\right)+ \\
\text { crude oil + Mineral salt medium }\end{array}$ \\
\hline D & $\begin{array}{c}\text { Myroides odoratimimus }\left(1 \mathrm{ml} \text { of } 2.5 \times 10^{6}\right)+\text { crude } \\
\text { oil + Mineral salt medium }\end{array}$ \\
\hline E & $\begin{array}{c}\text { Lysinibacillus species }\left(1 \mathrm{ml} \text { of } 2.1 \times 10^{6}\right)+\text { crude oil } \\
+ \text { Mineral salt medium }\end{array}$ \\
\hline F & $\begin{array}{c}\text { Acinetobacter species + Enterobacter hormaechei } \\
+ \text { Myroides odoratimimus + Lysinibacillus species } \\
(0.25 \text { ml each) + crude oil + Mineral salt medium }\end{array}$ \\
\hline
\end{tabular}

Table 1: Experimental Set Ups.

\section{Bioremediation Procedure}

Each of the bioremediation experimental set-ups was incubated at room temperature. The set-ups were agitated manually three times daily to aid aeration and even distribution of crude oil. Content of the experimental set ups was analyzed for total viable bacteria counts (TVBC) and total petroleum hydrocarbon (TPH) at weekly intervals for 35 days. TVBCs for each set-up were enumerated using spread plate method on nutrient agar and incubated at $37^{\circ} \mathrm{C}$ for 24 hours. After which, colonies that developed on the nutrient agar plates were counted and recorded as numbers of total viable bacteria obtained. TPH values were determined using Gas Chromatography method.

\section{Results}

\section{Population Changes of Viable Bacteria During Remediation of TPH}

The total viable bacterial counts are shown in Table 2. The A set up (control) which contained only crude oil recorded zero total viable bacterial counts on day 1 and day 7 while day 21 and day 35 had total viable bacterial counts of $1.0 \times 10^{5} \mathrm{CFU} / \mathrm{ml}$ and $1.8 \times 10^{5} \mathrm{CFU} / \mathrm{ml}$ respectively. The B set up that contained Acinetobacter species recorded $1.65 \times 10^{5} \mathrm{CFU} / \mathrm{ml}$ on day 1 with progressive increase in the total viable bacterial counts towards the end of experiment. Experimental set ups C and D containing Enterobacter hormaechei and Myroides ordaratimimus obtained counts of $2.69 \times 10^{6} \mathrm{CFU} / \mathrm{ml}$ and $1.90 \times 10^{6} \mathrm{CFU} / \mathrm{ml}$ respectively on day 1 ; on day 7 the total viable bacterial counts decreased in both set ups and increased again on day 21 and day 35. Lysinibacillus species ( $E$ set up) counts on day 1 were $2.75 \times 10^{6} \mathrm{CFU} / \mathrm{ml}$, which decreased on day 7 and day 21 , and increased again on day 35. The mixed culture set up (F) increased progressively from the beginning to the end of experiment.

\begin{tabular}{|c|c|c|c|c|c|c|}
\hline Day(s) & Control & $\begin{array}{c}\text { Acinetobacter } \\
\text { species }\end{array}$ & $\begin{array}{c}\text { Enterobacter } \\
\text { hormaechei }\end{array}$ & $\begin{array}{c}\text { Myroides } \\
\text { odaratimimus }\end{array}$ & $\begin{array}{c}\text { Lysinbacillus } \\
\text { species }\end{array}$ & $\begin{array}{c}\text { Mixed culture } \\
\text { of 4 species }\end{array}$ \\
\hline 1 & 0 & $1.65 \times 10^{5}$ & $2.69 \times 10^{6}$ & $1.90 \times 10^{6}$ & $2.75 \times 10^{6}$ & $3.44 \times 10^{6}$ \\
\hline 7 & 0 & $2.35 \times 10^{6}$ & $1.90 \times 10^{6}$ & $1.52 \times 10^{6}$ & $1.89 \times 10^{6}$ & $1.42 \times 10^{7}$ \\
\hline 21 & $1.0 \times 10^{5}$ & $3.22 \times 10^{6}$ & $2.66 \times 10^{6}$ & $2.05 \times 10^{6}$ & $1.13 \times 10^{6}$ & $1.50 \times 10^{7}$ \\
\hline 35 & $1.8 \times 10^{5}$ & $1.52 \times 10^{6}$ & $1.28 \times 10^{7}$ & $8.88 \times 10^{6}$ & $1.48 \times 10^{7}$ & $2.19 \times 10^{7}$ \\
\hline
\end{tabular}

Table 2: Total Viable Bacterial Counts (CFU/ML) of the Experimental Set-up.

\section{Molecularly Identified Bacterial Isolates}

The molecularly identified bacterial isolates were shown to be Acinetobacter species, Enterobacter hormaechei, Myroides ordaratimimus and Lysinibacillus species. These bacterial species were used for the biodegradation of total petroleum hydrocarbon.

\section{Degradation of Total Petroleum Hydrocarbon}

Table 3 shows the initial concentration of the total petroleum hydrocarbon and the degradation by individual and mixed culture of bacteria. Concentration of total petroleum hydrocarbon on the initial day was $3241.47081 \mathrm{mg} / \mathrm{l}$. The A (control) option had the highest amount of $2823.32534 \mathrm{mg} / \mathrm{l}$ remaining on day 35 with removal of $12.9 \%$. The least amount of $212.21130 \mathrm{mg} / \mathrm{l}$ remaining was observed in the $\mathrm{F}$ treatment option that had the mixed culture with percentage removal of $93.5 \%$. This was followed by D set up with Myroides odoratimimus which had remaining TPH of $284.54994 \mathrm{mg} / \mathrm{l}$ and $91.2 \%$ removal. Acinetobacter species (B set up) had remaining TPH of $363.71647 \mathrm{mg} / \mathrm{l}$ with $88.8 \%$ removal. Enterobacter hormaechei (C set up) had remaining TPH of $383.44001 \mathrm{mg} / \mathrm{l}$ with $88.2 \%$ removal. Lysinibacillus species (E set up) recorded $472.69664 \mathrm{mg} / \mathrm{l}$ amount of TPH remaining with $85.4 \%$ removal. There was reduction in peak and its number in the various treatment options on day 35 as shown in Figure 1-6. 


\section{Open Access Journal of Microbiology \& Biotechnology}

\begin{tabular}{|c|c|c|c|}
\hline Content & Initial (mg/l) & Final (mg/l) & \% Remova \\
\hline Control (Crude oil + Mineral Salt Medium) & 3241.47081 & 2823.32534 & 12.9 \\
\hline Acinetobacter species + crude oil + Mineral salt medium & 3241.47081 & 363.71647 & 88.8 \\
\hline Enterobacter hormaechei + crude oil + Mineral salt medium & 3241.47081 & 383.44001 & 88.2 \\
\hline Myroides odoratimimus + crude oil + Mineral salt medium & 3241.47081 & 284.54994 & 91.2 \\
\hline Lysinibacillus species + crude oil + Mineral salt medium & 3241.47081 & 472.69664 & 85.4 \\
\hline $\begin{array}{c}\text { Acinetobacter species }+ \text { Enterobacter hormaechei }+ \text { Myroides odoratimimus }+ \\
\text { Lysinibacillus species + crude oil + Mineral salt medium }\end{array}$ & 3241.47081 & 212.2113 & 93.5 \\
\hline
\end{tabular}

Table 3: Bioremediation of Total Petroleum Hydrocarbon.

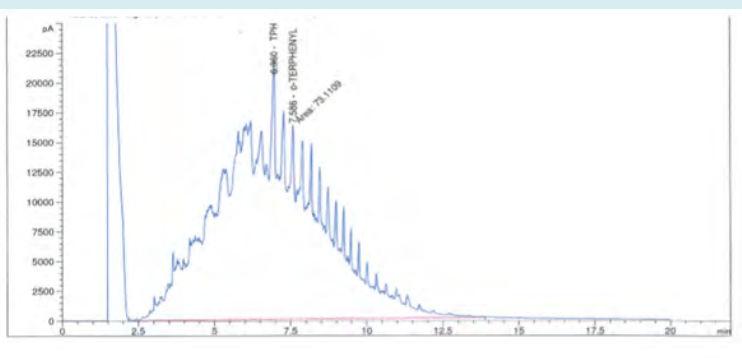

Totals

2823.32534

Figure 1: GC Profile Showing the Remediation of Total Petroleum Hydrocarbon (TPH) In the Control on Day 35.

Figure 2: GC Profile Showing the Remediation of Total Petroleum Hydrocarbon (TPH) By Acinetobacter Species on Day 35
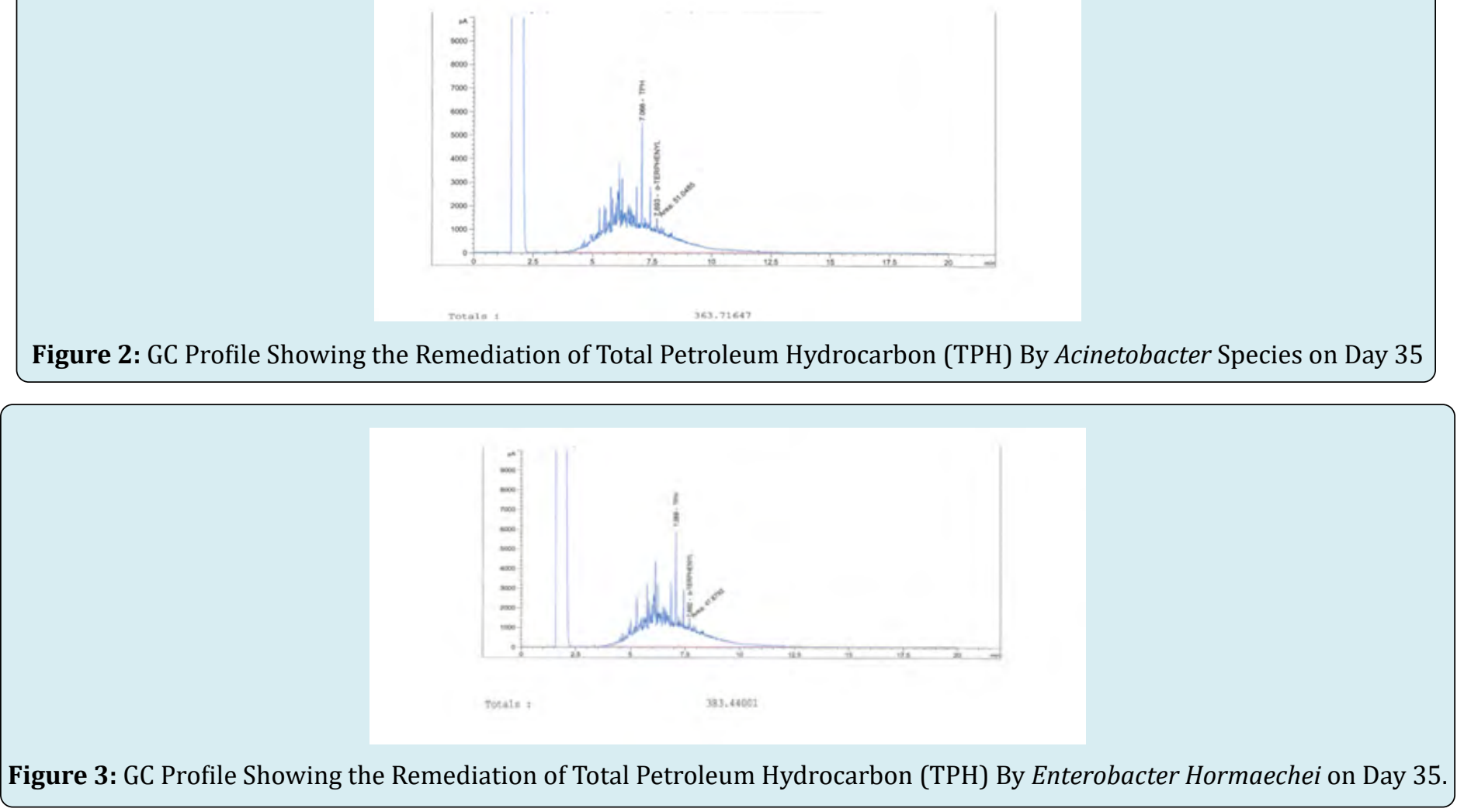


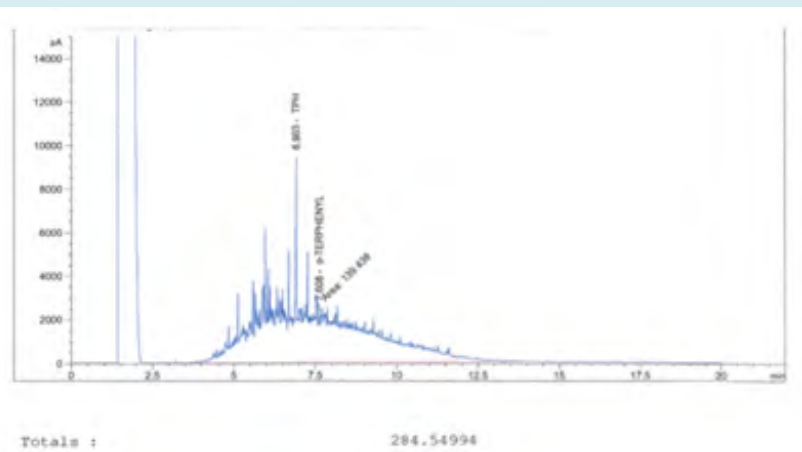

Figure 4: GC profile showing the remediation of total petroleum hydrocarbon (TPH) by Myroides odoratimimus on day 35.

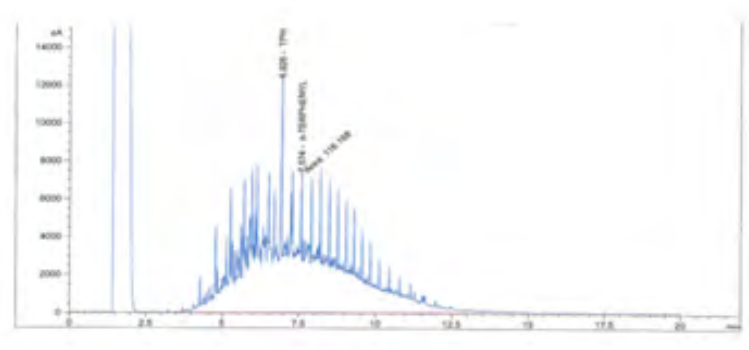

Figure 5: GC Profile Showing the Remediation of Total Petroleum Hydrocarbon (TPH) By Lysinibacillus Species on Day 35.

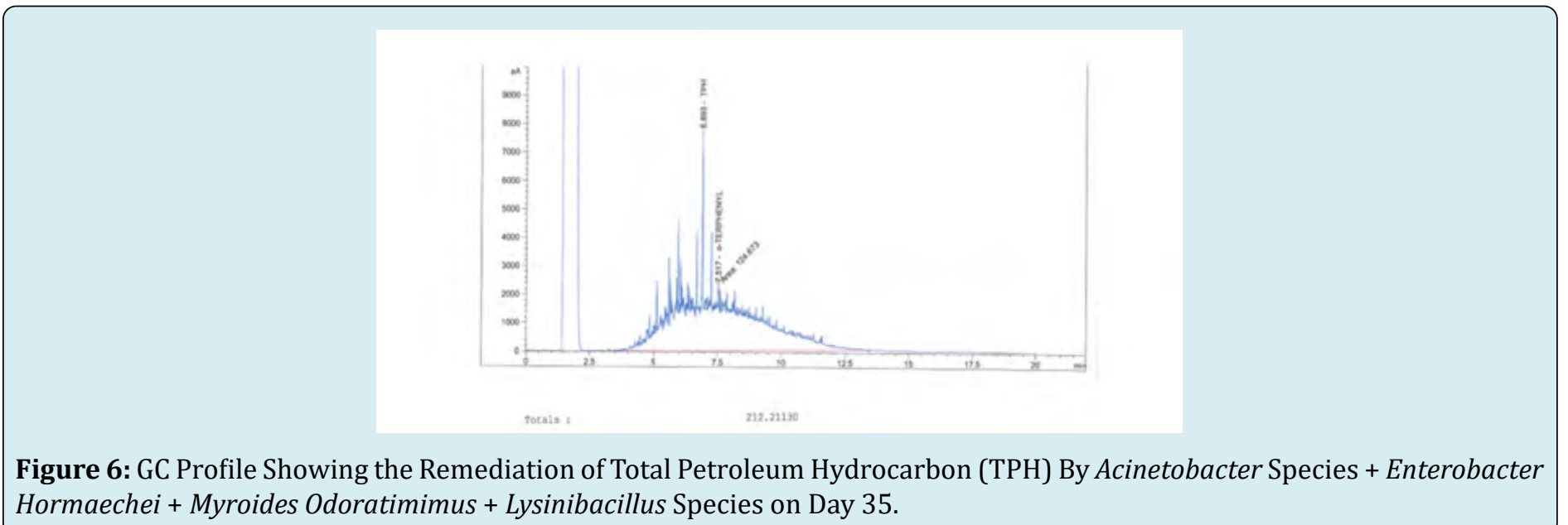

\section{Discussion}

Counts of total viable bacteria fluctuated throughout the period of the experiment in course of remediation of total petroleum hydrocarbon. The control samples recorded zero count on day 1 and day 7 , but had viable counts on day 21 and day 35 respectively. Total viable bacterial counts for Acinetobacter species and the mixed culture increased progressively from day 1 to day 35 . This could be attributed to the gradual utilization of hydrocarbon by the microbes. Enterobacter hormaechei and Myroides odaratimimus total viable bacterial counts reduced during day 1 and day 7 and increased thereafter on day 21 and day 35. Lysinibacillus species reduced in counts from day 1 to day 21 but increased on day 35. The decrease in counts after day 1 for Enterobacter hormaechei and decrease on day 7 and day 21 for Lysinibacillus species counts could be attributed to toxic effects of the hydrocarbon contents on 


\section{Open Access Journal of Microbiology \& Biotechnology}

the organisms. It is well known that hydrocarbon degrading bacteria occur in a wide variety of environments particularly in areas with presence of petroleum production activity. The use of native or indigenous microbiota for bioremediation is of great interest since it is more useful and beneficial than commercial inoculants [11].

The bacteria isolated from oilfield wastewater samples were identified as Acinetobacter species, Enterobacter hormaechei, Myroides odoratimimus and Lysinibacillus species. These microorganisms were used for the biodegradation of total petroleum hydrocarbon in this study. The ability of the organisms to degrade total petroleum hydrocarbon as single and mixed culture was examined, and varied with the species. Degradation of total petroleum hydrocarbon by Acinetobacter species showed percentage reduction of $88.8 \%$ at the end of the experiment. Enterobacter hormaechei had reduction of 88.2\%, Myroides odoratimimus 91.2\% and Lysinibacillus species $85.4 \%$ at the end of the experiment. The mixed culture had reduction of $93.5 \%$ at the end of the experiment. The highest percentage reduction of total petroleum hydrocarbon was in the mixed culture which was followed by the treatment with Myroides odoratimimus. The least reduction in TPH was observed in the control which recorded reduction of $12.9 \%$. This represents natural attenuation of crude oil which has been shown to be generally slow. The individual isolates demonstrated high level reduction of total petroleum hydrocarbon as shown in the percentage reduction obtained and reduction in the graphs of Gas Chromatography. Acinetobacter species have been found to play vital role in petroleum hydrocarbon degradation [12]. Enterobacter hormaechei is a coilform bacteria and its ability to degrade total petroleum hydrocarbon have also been reported by several researchers [13,14]. Divya, et al. [15] reported the degradation of diesel hydrocarbon by Myroides odoratimimus. Ashikodi and Abu, et al. [16] also reported the degradative potential of Lysinibacillus species. Results of degradation of TPH clearly showed that mixed culture of bacteria had the highest percentage removal of total petroleum and was proved to be most efficient. This could be attributed to the collective effort of the individual bacteria that formed the mixed culture. The higher degradation rate and microbial activity observed in the mixed culture may be related to shift in importance of one metabolic pathway over another possibly as a result of microbial synergism. This agrees with Friello, etal. [17] who reported that a wide variety of metabolic and physiological factors are required for the degradation of different compounds in diesel oil. Similarly Adebusoye, et al. [18] demonstrated that mixed culture of microbial community is required to complete biodegradation of crude oil pollutants because the hydrocarbon mixtures differs markedly in volatility, solubility and susceptibility to degradation and the necessary enzymes needed cannot be found in a single organisms. This coincides with Al-Saleh, et al. [19] who reported that individual microorganisms metabolize only a limited range of hydrocarbon substrates and crude oil is made up of mixture of compounds, such that biodegradation of it requires mixture of different bacterial groups or consortia functioning to degrade a wide range of the hydrocarbon components. Several reports [20,3] have confirmed microbial consortia as better degraders than individual pure isolates. In a culture, some species utilize intermediates of degradation of the original hydrocarbon produced by other members of the culture leading to a complete degradation of the oil [21]. Thus, a mixed culture is a better inoculum for bioremediation. Degradation of petroleum involves progressive or sequential reactions, in which certain organisms may carry out the initial attack on petroleum constituents. This produces intermediate compounds that are subsequently utilized by a different group of organisms in the process that results in further degradation [22]. Generally speaking the individual species in this study proved effective in degradation of TPH as all of them had between $85 \%$ and $91 \%$ removal of total petroleum hydrocarbon.

\section{Conclusion and Recommendation}

The potentials of some bacteria isolated from oilfield wastewater in this study to remediate total petroleum hydrocarbon were demonstrated and the organisms were found to have such ability. The microbial species obtained effectively utilized the total petroleum hydrocarbon during the degradation experiment. The study showed that the individual species possess high capability to degrade total petroleum hydrocarbon, however mixed culture of the individual isolates was more efficient in the remediation experiment. These bacteria can be harnessed and used for cleanup of crude oil contaminated environment.

\section{References}

1. Colwell RR (1977) Ecological aspects of microbial degradation of petroleum in the marine environment. CRC Crit Rev Microbiol 5(4): 423-445.

2. Lemos JLS, Rizzo AC, Millioli VS, Soriano AU, Sarquis MIM, et al. (2002a) Petroleum degradation by filamentous fungi. ${ }^{\text {th }}$ Annual International Petroleum Conference, October, pp: 22-25.

3. Obire 0, Aleruchi 0, Wemedo SA (2020) Fungi in biodegradation of polycyclic aromatic hydrocarbons in oilfield wastewater. Acta Scientific Microbiology 3(4): 220-224.

4. Wemedo SA, Obire O, Orubite KO (2012) Physicochemical quality of an oilfield wastewater in Nigeria. Asian J Research Chem 5(3): 425-432. 


\section{Open Access Journal of Microbiology \& Biotechnology}

5. Aleruchi 0 , Obire 0 (2019) Impact of various concentrations of oilfield wastewater on soil microorganisms. e-Journal of Science and Technology 14(3): 31-41.

6. American Public Health Association (1995) Standard methods for the examination of water and wastewater. $20^{\text {th }}$ (Edn.), American Public Health Association (APHA). American Water Works Association and Water Environment Federation, USA.

7. Prescott LM, Harley JP, Klien DA (2005) Microbiology $6^{\text {th }}$ (Edn.), McGraw Hill London, pp: 135-140.

8. Saitou N, Nei M (1987) The neighbor-joining method: A new method for reconstructing phylogenetic trees. Mol Biol Evol 4(4): 406-425.

9. Felsenstein J (1985) Confidence limits on phylogenies: An approach using the bootstrap. Evolution 39(4): 783791.

10. Jukes TH, Cantor CR (1969) Chapter 24-Evolution of protein molecules. Mammalian Protein Metabolism 3: 21-132.

11. Rocha LL, Colares GB, Angelim AL, Grangeiro TB, Melo VMM (2013) Culturable Populations of Acinetobacter Can Promptly Respond to Contamination by Alkanes in Mangrove Sediments. Mar Pollut Bull 76(1-2): 214-219.

12. Sarkar P, Roy A, Pal S, Mohapatra B, Kazy SK, et al. (2017) Enrichment and characterization of hydrocarbondegrading bacteria from petroleum refinery waste as potent bioaugmentation agent for in situ bioremediation. Bioresour Technol 242: 15-27.

13. Majida K, Al-Awadhi H, Radwan S (2017) Coliform bacteria for bioremediation of waste hydrocarbons. Biomed Res Int.

14. Nduka JK, Umeh LN, Okerulu IO, Umedum LN, Okoye HN (2012) Utilization of different microbes in bioremediation of hydrocarbon contaminated soils stimulated with inorganic and organic fertilizers. J Pet Environ Biotechnol 3(2): 116.

15. Divya UK, Saranya A, Suganthi R (2018) Diesel hydrocarbons biodegradation by Myoides odoratimimus. World News of Natural Sciences 20: 182-195.

16. Ashikodi AO, Abu GU (2019) Hydrocarbon degradation potential of some hydrocarbon utilizing bacterial species associated with Kenaf (Hibiscus cannabinus L.) plant. Int Res J Biological Sci 8(1): 10-19.

17. Friello DA, Myloie JR, Chakrabarty AM (2001) Use of genetically engineered multi-plasmid microorganisms for rapid degradation of fuel hydrocarbons. International Biodeterioration and Biodegradation 48(1-4): 233-242.

18. Adebusoye SA, Illori MO, Amund O0, Teniola OD, Olatope SO (2007) Microbial degradation of petroleum hydrocarbons in a polluted tropical stream. World Journal of Microbiology and Biotechnology 23: 11491159.

19. AL-Saleh E, Drobiova H, Obuekwe C (2009) Predominant culturable crude oil-degrading bacteria in the coast of Kuwait. International Biodeterioration and Biodegradation 63(4): 400-406.

20. Wemedo SA, Nrior RR, Ike AA (2018) Biodegradation potential of bacteria isolated from crude oil polluted site in South South, Nigeria. Journal of Advances Microbiology 12(2): 1-13.

21. Facundo JMR, Vaness HR, Teresa ML (2001) Biodegradation of diesel oil in soil by a microbial consortium. Water, Air, and soil Pollution 128: 313-320.

22. Karick N (1977) Alternation in petroleum resulting from physical-chemical and microbiological factors. In: DC Malins (Eds.), Effect of petroleum on arctic and Subarctic Environments and Organisms, Nature and Fate of Petroleum. Academic Press Inc., New York 1: 225- 299. 